\title{
Analysis on the Education Mechanism of the "Learning Power" Platform from the Perspective of Media Convergence
}

\author{
Zhi Li* \\ College of Marxism, Henan Polytechnic University, Jiaozuo 454000, Henan Province, China \\ *Corresponding author: Zhi Li, 18697373583@163.com
}

\begin{abstract}
As a media learning platform, the "Learning Power" platform integrates the advantages of the internet, big data, and new media. Through the supply of massive explicit and implicit learning resources as well as the construction of the interactive space of "Learning Power," it fully embodies the education mechanism of moral education. Specifically, it is reflected in the distinctive political position and the education goal mechanism of "moral education," the education operation mechanism of "explicit and implicit unity," the learning mechanism of "autonomy and cooperation integration," and the feedback incentive mechanism of "gamification." The organic combination and interactive operation of these four mechanisms form a collaborative education mechanism system of goal orientation, education operation, learning process, and feedback incentive.
\end{abstract}

Keywords: Media integration; "Learning Power" platform; Education mechanism

Publication date: October 2021; Online publication: October 29, 2021

\section{Introduction}

In order to enhance the attractiveness and appeal of educational activities, it is necessary to strengthen the internet thinking and integrate new media as well as new technologies into education. Media convergence, based on the advantages of the internet, new media, and information technology, is gradually becoming an important carrier for theoretical learning. As a product of the media horizon, the "Learning Power" platform can access explicit contents, such as news, ideas, and learning theories, as well as implicit resources, such as audios, video, and images. In addition, the interactive space of "Learning Power" has been established, and the feedback and incentive elements of the game are integrated. Through the coordinated operation of all the links and elements, the function of this online education platform is given full play. Therefore, the "Learning Power" platform forms a set of educational operation mechanisms, learning mechanisms, and feedback incentive mechanisms as well as effectively improves appeal and affinity toward educational activities.

2. The origin of the education mechanism of "Learning Power" from the perspective of media convergence

"Mechanism" is the concept of mechanics - the mutual relationship between internal parts and their working principle during the operation of a machine. With the development of cross-integration of disciplines, mechanisms have been widely studied between humanities and various fields, such as economics, politics, sociology, ethics, and education. It is an inevitable choice to establish an efficient education mechanism in line with the trend of the times and the needs of the development in order to ensure 
that education is more attractive, amiable, targeted, and effective in the new era. "Learning Power" relies on the advantages of media convergence to create a learning platform with educational functions. Its education mechanism is essentially the innovation and development of the education working mechanism from the perspective of media.

Media convergence is derived from the all-round consideration of the development of media integration. It involves the use of the internet, big data, and new media technology to enable the organic integration of traditional media and emerging media, thus providing the latest, fastest, and most convenient services or products for the public ${ }^{[1]}$. Different from omnimedia, media convergence has more emphasis on resource integration, content integration, publicity integration, and mechanism integration through the comprehensive integration of resources ${ }^{[2]}$. A media convergence platform is a new communication way to integrate text, audio, image, network, communication, and others.

As an essential carrier of online education, "Learning Power" provides people with time-space boundaries and powerful educational content, builds the physical scale of diversified education forms, and creates a multidimensional interactive learning model that breaks through disciplinary boundaries. From this point of view, "Learning Power" has effectively realized the organic unity of "whole-process education," "all-round education," and "overall education." In addition, "Learning Power" makes use of the advantages of the internet and big data, integrates traditional media, network media, text learning, audio and video learning, as well as other forms in creating an epoch-oriented, networked, and game-based education mechanism.

\section{The education operation mechanism of "explicit and implicit unity"}

Education operation mechanism is a coordinated, flexible, and efficient operation mechanism established to ensure the realization of educational goals and tasks. In education, both the traditional explicit indoctrination and the implicit infiltration have their advantages and disadvantages. "Learning power" has established an education operation mechanism of "explicit and implicit unity," which provides abundant theoretical educational resources and implicit educational resources of life, literature, art, and science to the learners. The "Learning Power" platform can eliminate the learners' resistance to the indoctrination of traditional education and ensure the effectiveness of educational function through precise educational positioning and novel presentation. It can also isolate the intrusion of harmful information on the network and overcome the "disorder" of implicit education.

In the process of educating people, explicit education refers to the direct instillation of planned and purposeful education by educators in the form of classroom teaching and special lectures. Implicit education refers to the "infiltration" and "stealth" of implied educational goals, in order for people to imperceptibly deepen their thoughts. "Learning Power" realizes the unity of explicit education and implicit education through the provision of explicit resources and implicit resources. First of all, explicit resources are used in the direct and open educational process of education ${ }^{[3]}$. In regard to "Learning Power," explicit educational resources include current political news, such as text types, thoughts, time evaluation, and theoretical learning materials, as well as educational and indoctrination learning resources, such as audios, learning videos, theoretical lecture halls, MOOCs, and so on. A remarkable feature reflected is that it has clear educational goals and educational content along with a clear educational orientation. Learners can obtain theoretical knowledge through explicit educational resources and deepen their understanding of theory through various forms of learning. Secondly, implicit resources are unconsciously or indirectly educated, in which people unconsciously receive education ${ }^{[3]}$. The implicit educational resources of "Learning Power" do not only include auditory dramas, operas, music, and poetries, but also visual experience of science and technology, nature, literature, art, etc. The implicit education form of "Learning Power" is through the appreciation and perception of beauty, and then realizing the perception and sublimation of value concept 
and ideology. In implicit resources, there are no clear educational goals, but there are implied educational contents and values everywhere. It is necessary to recognized that in the learning of explicit educational resources, educators may form "indoctrination," which would affect the learning effect as well as the understanding and deepening of theoretical content. It is mandatory for educators to accept the educational resources from the "heart" in order to achieve a beneficial effect. The instillation of implicit educational resources is to penetrate the contents into the minds of the educators through implied educational goals. It is possible that a deviation from the learning goals and content may occur as a result of the inability to grasp them reasonably. Neither the explicit way nor the implicit way can guarantee the full realization of the educational function.

"Learning Power" takes advantage of media convergence and big data to provide rich explicit and implicit educational resources. It sets up various education forms such as audios, videos, as well as questions and answers. Based on highlighting the function of explicit education, the implicit education content is integrated to ensure the effective operation of the education operation mechanism of "explicit and implicit unity." First, from the perspective of the nature of the platform, "Learning Power" has an obvious educational function. The platform has many learning resources, and there is no other irrelevant information, such as entertainment or gossips. It is a pure theoretical knowledge platform. Second, from the perspective of educational operation, the platform provides diversified educational methods. One of them is the text theory. The platform transforms text information on books into dozens of "data packets" and moves the text theory to the screen, realizing the learning of text anytime, anywhere, and at will. The platform provides theoretical learning, ideological research, and exposure to multidisciplinary fields of politics, history, geography, and literature, enriching the content of explicit education, broadening the thinking and vision of education, and ensuring the effective operation of explicit education. The second is to provide learners with audio and video appreciation. "Learning power" offers many types of music, images, as well as radio and video contents, with implied morality, values, classical thoughts, and excellent traditions. Learners can deeply explore their thoughts and values by listening to music and appreciating classic pictures. In this manner, "Learning power" implicitly realize the educational effect, enrich the educational narrative mode, and improve the acceptance toward education.

\section{The learning mechanism of "autonomy and cooperation"}

In regard to "Learning Power," the learning mechanism of "autonomy and cooperation" refers to a learning mode supported by rich and diverse contents as well as forms. In addition, the "Learning Power" platform is a guarantee. In a classroom created from this learning mechanism, teachers only need to set the theme and guide students to select the learning method and content for themselves in the platform. Students are placed in an environment that provides an independent choice and conscious learning of the theoretical content. Forming their own understanding of certain theories, they would be encouraged to share with their groups in order to promote communication with one another. Finally, teachers would then summarize and comment. The elements are interlinked, effectively realizing the internalization of theoretical knowledge and greatly improving the effectiveness of education.

Autonomous learning is the process in which learners independently activate and control their cognition, emotions, and behaviors to systematically achieve personal goals ${ }^{[4]}$. Cooperative learning refers to organizing group activities to teach in order to promote students' learning to the greatest extent ${ }^{[4]}$. "Learning Power," based on the perspective of media convergence, does not only provide resources for independent learning, but also build a platform for cooperative learning. First of all, the independent learning function of "Learning Power" is based on rich learning resources. Taking advantage of the platform's resources, teachers would only need to come up with the plans, goals, and tasks in advance, while students would independently and actively choose their own learning methods according to their 
understanding of the goals. Students can establish a preliminary understanding of relevant theories through the study of text materials, keyword search, and the selection of relevant theoretical interpretations as well as MOOC interpretations. Secondly, the cooperative learning function of "Learning Power" uses the construction a strong communicative social platform as the carrier. Through different forms and methods of learning, students would comprehensively compare and ponder about different theoretical interpretations, and then construct their own theoretical system. Thereafter, their understanding and views can be shared among their groups for exchange and discussion. After mutual exchanges and sharing among the students, teachers can comment and summarize the students' views. The independent learning platform provided by "Learning Power" has broken through the traditional classroom teaching mode of "enlightenment," which can eliminate learners' negative emotions and deepen their understanding as well as mastery of theories. In addition, "Learning Power" can effectively realize the "whole-course education" beyond time and space by creating a learning environment for learners. The cooperative learning provided by the platform has eliminated the "one-to-many" mode of teaching and realized the education of all staffs by "many-to-one" and "many-to-many." Through the integration of independent learning and cooperative learning, "Learning Power" effectively improves the effectiveness of learning while eliminating students' rebellious psychology toward learning. Both independent learning and cooperative learning are mature and applied based on the development of the new educational technology concept. Integrating independent learning with cooperative learning and introducing the educational process are of great significance to improving the effectiveness and affinity of education.

The operation and development of the learning mechanism of "autonomy and cooperation" is the premise of massive learning resources and a "power" communication platform. The "Learning Power" platform is a platform with massive learning resources based on the internet. It does not only provide a variety of learning forms from explicit education to implicit education, but also rich learning content from texts, audios, videos, and MOOCs, to interpretations and learning perceptions of experts. It provides rich content and forms for independent learning and opens up the theoretical vision of independent learning. The use of the search engine has opened the Pandora's box for independent learning. As a theoretical learning platform, "Learning Power" provides a "free" environment without spatial and space constraints for independent learning and effectively guarantees the realization of independent learning. Second, "Learning Power" has built a convenient interactive space. Therefore, the platform builds a powerful communication learning space based on interactive thinking and provides students with a "tribe" for interactive learning. Teachers can form different learning groups according to different classes, interests, and hobbies. Students can share their views and high-quality contents as well as form new understanding through mutual communication and discussion. Through cooperative exploration, they would be able to deepen their understanding of relevant theoretical knowledge. It has realized the effective integration of independent learning and cooperative learning.

\section{The feedback incentive mechanism of "gamification"}

The process of educational development is a spiral cognitive process and a bidirectional ascending cycle of theoretical knowledge from internalization to externalization as well as continuous internalization. Getting through the double cycle of education is crucial to improve its effectiveness. Moreover, timely and effective feedback incentive is the key to open the double cycle. The "Learning Power" platform draws from the "gamification" feedback incentive mode and creates an intuitive, timely, and effective feedback incentive mechanism via solving problems, receiving points, ranking, and other ways in realizing timely feedback and effective incentives.

"Feedback" is the result of the control signal generated and the transmission back from the accused system. Feedback is an important link of the control process. "Incentive" is to stimulate and encourage 
based on certain needs. In ideological and political education activities, timely feedback and effective incentives are essential and important links. The current lack of educational timeliness and effectiveness is mostly due to the lack of timely feedback and incentives [5]. "Learning Power" takes advantage of challenges, points, and rankings to create a game-like feedback and incentive mechanism, forming an intuitive two-way cycle. First, answering the challenge link. The platform has set up six modes: weekly answer, daily answer, special answer, challenge answer, two-person challenge, and multi-person challenge. The theoretical knowledge content is in the form of questions, and points are given by answering those questions. Among them, the two-person challenge and multi-person challenge provide an online "confrontation." Educators would be able to gauge their lack of certain knowledge points while comparing with others in these competitions. This would stimulate their enthusiasm for further learning and fully activate their endogenous motivation to actively learn and improve themselves. The second is the integral mode of "Learning Power." There are various methods to obtain points on the platform, including reading articles, audio-visual learning, answering challenges, sharing comments, etc. In the process of education, timely feedback is conducive to determine the imbalance in the process of education and execute targeted corrections as well as adjustments. The application of the integral mode provides an intuitive form for the discovery of problems in time. Intuitive feedbacks on the learning length, learning content, and learning effect at each stage can be provided through the integral, so that teachers can adjust and improve in time according to the problems reflected by the integral. At the same time, the platform also offers a pointexchange mall, which enables the exchange of virtual points into physical rewards, thus stimulating the enthusiasm for learning to a certain extent. Third, the ranking board. The platform intuitively shows the learning points through the form of ranking and effectively realizes the feedback of educational effect. Through the ranking list, educators are able to gauge their strengths and shortcomings; in addition, they would be able to timely understand the extent of their learning and knowledge mastery. Other than that, the ranking can also stimulate their enthusiasm for learning as well as enhance their sense of achievement and gain from learning.

\section{Conclusion}

The education mechanism of "Learning Power" does not exist in isolation but has a high degree of internal correlation and jointly realizes the play of education function through the synergistic action of various mechanisms. Among them, the education operation mechanism of "explicit and implicit unity" innovates the process of education and eliminates the boredom generated in the process of traditional education. The learning mechanism of "autonomy and cooperation" innovates the learning process, provides a new learning method for educators, and effectively improves the autonomy as well as effectiveness of learning. The feedback incentive mechanism of "gamification" is a feedback incentive process of creating educational activities by learning from "gamification" elements as well as realizing timely feedback on the effect and goals of education. Through the effectiveness of the operation process, the interactivity of the learning process, and the timeliness of the feedback incentive process, a complete education would be effectively realized.

\section{Disclosure statement}

The author declares that there is no conflict of interest.

\section{References}

[1] He D, 2014, Media Convergence: Create a New Mainstream Media. Guangming Daily, (10). 
[2] Li W, 2017, Cross-media All-Media Integration of Media-Related Conceptual Change and Practical Evolution of Media Convergence. News and Writing, (06): 38-40.

[3] Chen H, 2007, Ideological and Political Educational Resources Theory. Central China Normal University.

[4] Zhang Y, 2018, Independent Cooperation Inquiry: The Transformation of Students' Learning Mode. Journal of East China Normal University (Education Science Edition), (01): 22-28, 160.

[5] Feng G, Wang D, 2017, Construction of Ideological and Political Education Based on the Enlightenment of Game System. Ideological Education Research, (08): 21-25. 